\title{
A Case of Anaplastic Large Cell Lymphoma Presenting in Leukemic Phase
}

\author{
Rahul Ravilla ${ }^{1 *}$, Appalanaidu Sasapu ${ }^{1}$, Jeanette M Ramos ${ }^{2}$ and Konstantinos Arnaoutakis ${ }^{1}$ \\ ${ }^{1}$ Department of Hematology-Oncology, University of Arkansas for Medical Sciences, Little Rock, AR, USA \\ ${ }^{2}$ Department of Pathology, University of Arkansas for Medical Sciences, Little Rock, AR, USA
}

*Corresponding author: Rahul Ravilla, Department of Hematology-Oncology, University of Arkansas for Medical Sciences, Little Rock, 4301 W. Markham St., Slot \#634, Arkansas-72205, AR, USA, Tel: 501-313-9405; Fax: 501-686-6001; E-mail: rravilla@uams.edu

Received date: Sep 22, 2015, Accepted date: Oct 24, 2015, Publication date: Oct 31, 2015

Copyright: (C) 2015 Ravilla R, et al. This is an open-access article distributed under the terms of the Creative Commons Attribution License, which permits unrestricted use, distribution, and reproduction in any medium, provided the original author and source are credited.

\begin{abstract}
Anaplastic lymphoma kinase (ALK) with positive Anaplastic Large Cell Lymphoma (ALCL) is has a distinct entity among the peripheral T-cell lymphomas. With a 5-year survival rate of $70 \%$, it carries one of the best prognoses among peripheral T cell lymphomas. In rare instances, ALK positive ALCL presents in leukemic phase and it has a very poor prognosis with negligible number of cases reporting a survival rate of beyond one year. Following Case study as a research technique, the researchers tried to discuss about a patient affected by ALK positive ALCL in leukemic phase, associated with $\mathrm{t}(2 ; 5)(\mathrm{p} 23 ; \mathrm{q} 35)$. The patient reported the clinic with a three week history of breathlessness, fever, diarrhoea, and axillary lymphadenopathy. His condition deteriorated in spite of rapid initiation of chemotherapy, and he succumbed to the high tumor burden. The study concludes that early diagnosis and institution of treatment is important in this regard. As this is a rare medical condition, with negligible alternative solutions, the present study underlines the need for further research in this area, emphasizing the need for newer therapies. It particularly stresses the need to examine the association of EBV and ALCL, with a specific reference to ALK-negative ALCL.
\end{abstract}

Keywords: ALK positive; Anaplastic large cell lymphoma; Leukemic presentation; EBV

\section{Introduction}

Anaplastic large cell lymphoma (ALCL) is a relatively rare type of neoplasm, comprising $3 \%$ of the adult onset Non-Hodgkin Lymphoma (NHL) and $10-15 \%$ of pediatric NHL cases. It has unique immunohistochemistry (IHC), staining positive for CD30, a marker for Hodgkin's lymphoma along with co-expression of T-cell markers [1]. A subset (40-60\%) of ALCL cases have translocation $t(2 ; 5)$ (p23;q35), resulting in formation of Nucleophosmin-Anaplastic lymphoma kinase (NPM-ALK) protein, a trans-membrane tyrosine kinase receptor [2]. Other less common translocations involving ALK gene in cases of ALCL include $t(1 ; 2), t(2 ; 3), t(2 ; 17), t(2 ; 19), t(2 ; 22)$, $\mathrm{t}(2 ; \mathrm{X})$ and $\operatorname{inv}(2)[3]$.

ALK positive ALCL has a number of histological variants, but the majority present as the classic/common variant characterized by eccentric horseshoe-shaped nucleus containing "hallmark cells". ALK positive ALCL tends to affect children and young adults with higher male predilection. It carries a good prognosis with five year survival rate of more than $80 \%$ even in advanced stage [4]. Rarely ALCL presents in leukemic phase and its true incidence is unknown. The presence of high number of atypical lymphocytes in peripheral blood along with presence of $\mathrm{T}$ cell markers make it difficult to differentiate from T-cell leukemia. Epstein-Barr virus (EBV) is a known risk factor for several types of lymphoma but was not shown associated with ALK positive ALCL. We report an unusual case of a patient with ALKpositive ALCL presenting in leukemic phase, who had a history of infectious mononucleosis.

\section{Case}

A 31-year-old Caucasian man presented to an outside hospital with a three week history of breathlessness, fever, diarrhoea, and axillary lymphadenopathy. He was diagnosed with infectious mononucleosis 4 years ago. His white cell count on presentation was $15 \mathrm{~K} / \mathrm{uL}$. He was started on doxycycline for possible tick borne illness. Imaging with whole body CT scan showed diffuse lymphadenopathy on either side of diaphragm. His White cell count rapidly worsened to $85 \mathrm{~K} / \mathrm{uL}$. For suspected leukemia, he was started on hydroxyl urea and allopurinol and transferred to our facility.

His blood counts on arrival to our center showed White cell count $97 \mathrm{~K} / \mathrm{uL}$, hemoglobin $12.7 \mathrm{~g} / \mathrm{dL}$, platelets $128 \mathrm{~K} / \mathrm{uL}$, serum lactate 10 $\mathrm{mg} / \mathrm{dL}$ and Beta-2 microglobulin $12 \mathrm{mg} / \mathrm{dl}$. His peripheral blood smear showed leukocytosis including neutrophilia and a population of pleomorphic atypical cells, comprising $17 \%$ of leukocytes (Figure 1). Flow cytometry on peripheral blood and bone marrow showed an atypical population that expressed bright CD45 and co-expressed CD2, CD56, HLA-DR, CD13, and dim CD4. Bone marrow biopsy showed $50 \%$ cellularity. Large, atypical cells were observed in a blood clot adjacent to the biopsy and less frequently in the bone marrow biopsy. IHC stains demonstrated that the tumor cells were positive for CD30 and ALK and were distributed in a sinusoidal pattern in the bone marrow (Figure 2). These cells were negative for CD20, CD3, CD8, and EBER (EBV ISH stain). Interphase FISH demonstrated that $28 \%$ of cells had $\mathrm{t}(2 ; 5)(\mathrm{p} 23 ; \mathrm{q} 35)$.

He developed multi-organ failure requiring ventilator support and dialysis. We administered one cycle of Cyclophosphamide, Doxorubicin, Vincristine, and Prednisone (CHOP) to the patient. Unfortunately he succumbed to the illness shortly after finishing this chemotherapy. 


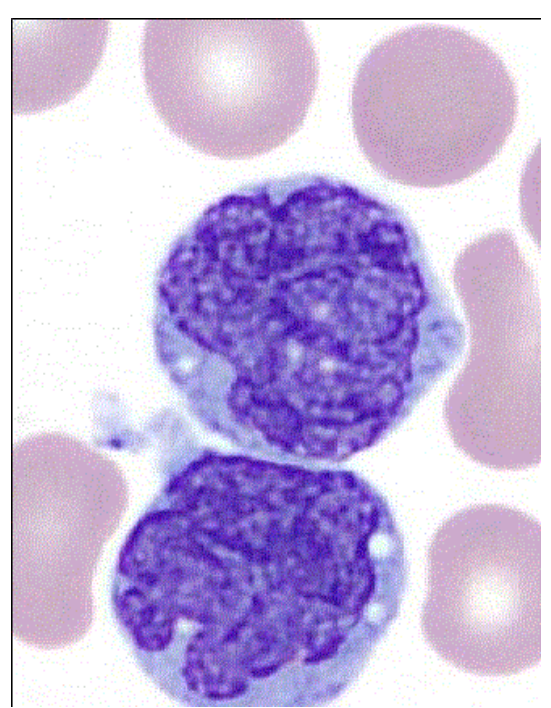

Figure 1: Cellavision high-power images of the atypical mononuclear cells showing irregular, folded nuclei, cytoplasmic blebbing, and cytoplasmic vacuoles.

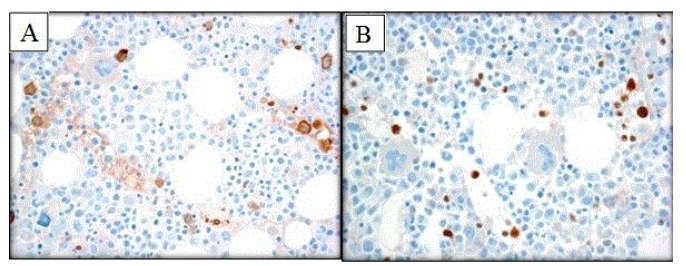

Figure 2: (A and B) CD30 and ALK immunohistochemical stains highlight the large atypical cells in the bone marrow biopsy, respectively, distributed in a sinusoidal pattern (400x). Note the nuclear and cytoplasmic staining of the ALK.

\section{Discussion}

Leukemic presentation of ALK positive ALCL is a rare entity among peripheral $\mathrm{T}$ cell lymphomas. Our literature search revealed only few cases and a single case series reported [5]. Due to presence of numerous atypical lymphocytes in peripheral blood, some of which have a more immature morphologic appearance, the diagnosis of acute leukemia was entertained and in this case was initially thought to be T cell leukemia. But availability of ALK and CD30 IHC-stains made the diagnosis possible in our case.

There are no clear risk factors associated with occurrence of ALCL. The role of EBV in ALCL is not clear with conflicting data from various case reports. A case series from North America did not find any evidence of EBV by in situ hybridization and LMP (Latent membrane protein) staining [6]. Our patient had history of infectious mononucleosis with no evidence of active EBV infection at time of ALCL diagnosis; the tumor cells were negative for the EBER ISH stain.

More than $80 \%$ of cases presenting in leukemic phase are of small cell variant as reported by Nguyen et al. [5]. Due to limited number of cases, the etiology for aggressive nature of this presentation is not well studied. More than half of the reported cases have complex karyotype. Our patient had typical translocation $\mathrm{t}(2 ; 5)$ with no additional abnormalities.

International Prognostic Index (IPI) is used to assess the prognosis for NHL and is based on age ( $>60$ years), number of extra-nodal sites $(>1)$, LDH level (above normal), disease stage (III/IV), and Eastern Cooperative Oncology Group (ECOG) performance status (PS 2-4) [7]. Our patient has 4 of these risk factors, which usually carries a 5year survival rate of $25-33 \%$. The overall 5 -year survival rate varies from $90 \%$ (IPI $0-1$ ) to $39 \%$ (IPI $\geq 2$ ) [8]. Other predictors for poor prognosis include beta-2 microglobulin level $>3 \mathrm{mg} / \mathrm{dL}$ and bone marrow involvement as found in our case.

Rapid white blood cell count elevation and clinical deterioration, as seen in this case, is a cause for early initiation of treatment. Even though $\mathrm{CHOP}$ based regimens remain the standard of treatment for ALK positive ALCL, especially in North America, these regimens have a poor response rate in leukemic presentation of ALCL. Most of the other regimens, including ESHAP (Etoposide, Methyl prednisone, Cytarabine, Cisplatin) and ICE (Ifosfamide, carboplatin, Etoposide) are generally used in relapsed cases. With Brentuximab Vedotin (CD30 antibody-drug conjugate ) approved for relapsed or treatment resistant ALCL cases [9], there are ongoing trials evaluating effectiveness of this agent when combined with $\mathrm{CHOP}$ regimen for induction [10]. Also showing promise is crizotinib, an ALK inhibitor initially approved for ALK positive non-small cell lung cancer and now in phase 3 clinical trials for ALK positive ALCL with phase 2 studies showing great response rates [11]. We hope that newer therapeutic agents will improve the remission and overall survival rates.

\section{Conclusion}

We conclude that leukemic presentation of ALK positive ALCL is a rare condition with very unfavorable prognosis. Considering its fulminant course, early diagnosis and institution of treatment is important. Even though CHOP based regimen is effective in usual presentation, leukemic phase has poorer outcomes. Due to rarity of condition the effectiveness of alternate regimens is debatable and there is need for further studies for newer therapies. The association of EBV and ALCL, especially ALK-negative ALCL, warrants further investigation.

\section{Conflicts of Interest}

The authors have no conflicts of interest to disclose.

\section{References}

1. Stein H, Mason DY, Gerdes J, O'Connor N, Wainscoat J, et al. (1985) The expression of the Hodgkin's disease associated antigen ki-1 in reactive and neoplastic lymphoid tissue: Evidence that reed-Sternberg cells and histiocytic malignancies are derived from activated lymphoid cells. Blood 66: 848-858.

2. Morris SW, Kirstein MN, Valentine MB, Dittmer K, Shapiro DN, et al. (1995) Fusion of a kinase gene, ALK, to a nucleolar protein gene, NPM, in non-Hodgkin's lymphoma. Science 267: 316-317.

3. Chiarle R, Voena C, Ambrogio C, Piva R, Inghirami G (2008) The anaplastic lymphoma kinase in the pathogenesis of cancer. Nat Rev Cancer 8: 11-23.

4. Gascoyne RD, Aoun P, Wu D, Chhanabhai M, Skinnider BF, et al. (1999) Prognostic significance of anaplastic lymphoma kinase (ALK) protein expression in adults with anaplastic large cell lymphoma. Blood 93: 3913-3921. 
Citation: Ravilla R, Sasapu A, Ramos JM, Arnaoutakis K (2015) A Case of Anaplastic Large Cell Lymphoma Presenting in Leukemic Phase. J Blood Disord Transfus 6: 316. doi:10.4172/2155-9864.1000316

Page 3 of 3

5. Nguyen JT, Condron MR, Nguyen ND, De J, Medeiros LJ, et al. (2009) Anaplastic large cell lymphoma in leukemic phase: extraordinarily high white blood cell count. Pathol Int 59: 345-353.

6. Herling M, Rassidakis GZ, Jones D, Schmitt-Graeff A, Sarris AH, et al. (2004) Absence of epstein-barr virus in anaplastic large cell lymphoma: A study of 64 cases classified according to world health organization criteria. Hum Pathol 35: 455-459.

7. Ziepert M, Hasenclever D, Kuhnt E, Glass B, Schmitz N, et al. (2010) Standard International prognostic index remains a valid predictor of outcome for patients with aggressive CD20+ B-cell lymphoma in the rituximab era. J Clin Oncol 28: 2373-2380.

8. Vose J, Armitage J, Weisenburger D, International T-Cell Lymphoma Project (2008) International peripheral T-cell and natural killer/T-cell lymphoma study: pathology findings and clinical outcomes. Journal of clinical oncology: official journal of the American Society of Clinical Oncology 26: 4124-4130.

9. Pro B, Advani R, Brice P, Bartlett NL, Rosenblatt JD, et al. (2012) Brentuximab vedotin (SGN-35) in patients with relapsed or refractory systemic anaplastic large-cell lymphoma: results of a phase II study. J Clin Oncol 30: 2190-2196.

10. http://clinicaltrials.gov/show/NCT01777152.

11. Farina F, Stasia A, Ceccon M, Redaelli S, Mologni L, et al. (2013) High Response Rates To Crizotinib In Advanced, Chemo resistant ALK+ Lymphoma Patients. ASH Annual Meeting Abstracts 122: 368. 